\title{
PENGARUH PENDIDIKAN KESEHATAN DENGAN METODE PEER GROUP TERHADAP PENGETAHUAN REMAJA PUTRI TENTANG KEPUTIHAN (FLUOR ALBUS)
}

\author{
Domas Nurchandra Pramudianti \\ Kebidanan, Universitas Muhammadiyah Banjarmasin, email: domaschandra@umbjm.ac.id
}

\begin{tabular}{l} 
INFO ARTIKEL \\
Riwayat Artikel: \\
Diterima: 29-05-2020 \\
Disetujui: 03-06-2020 \\
\hline Kata Kunci: \\
Peer Group \\
Pendidikan Kesehatan \\
Pengetahuan
\end{tabular}

\begin{abstract}
ABSTRAK
Abstrak: Pengetahuan remaja mengenai masalah kesehatan reproduksi memang masih minim, banyak remaja yang tidak mengetahui dampak dari keputihan. Pentingnya remaja mengetahui tentang keputihan agar wanita khususnya remaja mengetahui tentang keputihan, tanda gejala, penyebab, dan pencegahan keputihan upaya yang dilakukan yaitu dengan pendidikan kesehatan menggunakan metode peer group. Penelitian ini bertujuan untuk Mengetahui Pengaruh Pendidikan Kesehatan Menggunaan Metode Peer Group Terhadap Pengetahuan Remaja Putri Tentang Keputihan (Fluor Albus) di SMP 1 Muhammadiyah Banjarmasin. Penelitian ini menggunakan desain quasy eksperimental dengan rancangan pre-test and post-test without control dan menggunakan uji statistik paired t-test dengan teknik pengambilan sampel purposive Sampling. Jumlah sampel 30 responden. Hasil nilai pre-test dan pos-test pada kelompok intervensi 0,001 , hasil pre-test dan post-test pada kelompok kontrol 0,251. Hasil penelitian ini menunjukkan ada pengaruh pendidikan kesehatan menggunakan metode peer group terhadap pengetahuan remaja putri tentang keputihan (fluor albus).
\end{abstract}

\begin{abstract}
Adolescent knowledge about reproductive health issues is still minimal, many teenagers who do not know the impact of vaginal discharge. The importance of adolescents to know about vaginal discharge so that women especially teenagers know about vaginal discharge, signs, symptoms, causes, and prevention of vaginal discharge efforts undertaken namely by health education using peer group methods. This study aims to determine the effect of health education using the Peer Group Method on adolescent girls' knowledge about vaginal discharge (Fluor Albus) in SMP 1 Muhammadiyah Banjarmasin. This study used a quasy experimental design with a pre-test and post-test design without control and used a paired $t$-test statistical test with a purposive sampling technique. The sample size was 30 respondents. The results of the pre-test and post-test scores in the intervention group 0,001, the pre-test and post-test results in the control group 0.215. The results of the study have the effect of health education using peer group methods on the knowledge of young women about vaginal discharge (fluor albus)
\end{abstract}

\section{A. LATAR BELAKANG}

Remaja adalah masa transisi dari masa anak-anak ke masa remaja, individu mulai mengembangkan ciri-ciri abstrak dan konsep diri menjadi lebih berbeda. Batasan usia remaja adalah 10-24 tahun, ditandai adanya perubahan fisik, emosi dan psikis. Masa remaja terjadi pematangan organ reproduksi manusia dan sering disebut dengan masa pubertas (Ramauli \& Vindari, 2011).

Salah satu penyebab timbulnya masalah kesehatan reproduksi pada remaja adalah kurangnya pengetahuan mereka tentang hal-hal yang berkaitan dengan keputihan. Menurut WHO (World Health Organization), bahwa $75 \%$ dari seluruh wanita di dunia pasti akan mengalami keputihan paling sekali dalam seumur hidup dan sebanyak $45 \%$ akan mengalaminya 2 kali atau lebih dan keputihan yang paling sering terjadi disebabkan oleh candida albicans. Akibat dari keputihan sangatlah fatal bila lambat ditangani.Tidak hanya bisa mengakibatkan kemandulan dan hamil ektopik (kehamilan diluar kandungan) dikarenakan terjadi penyumbatan pada salur tuba, keputihan juga bisa merupakan gejala awal dari kanker leher rahim yang merupakan pembunuh nomor satu bagi wanita dengan angka insiden kanker servik mencapai 100 per 100.000 penduduk pertahun (Muhammad Darma, 2017).

Di Indonesia sebanyak Sebanyak $85 \%$ remaja di dunia hidup di daerah berkembang. Di Indonesia, jumlah remaja dan kaum muda berkembang sangat cepat (Kusmiran, 2011). Kasus keputihan di Indonesia semakin meningkat, pada tahun 2010, 52\% wanita di Indonesia mengalami keputihan, kemudian pada tahun 2011, 60\% wanita pernah mengalami keputihan, sedangkan tahun 2012 hampir 70\% wanita di Indonesia pernah mengalami keputihan, dan pada tahun 2013 
bulan januari hingga agustus hampir 55\% wanita pernah mengalami keputihan (Muhammad Darma, 2017).

Kesehatan reproduksi, sama halnya dengan kesehatan pada umumnya, adalah hak setiap manusia termasuk remaja. Untuk mampu mencapainya, diperlukan pengetahuan tentang kesehatan reproduksi yang benar dan komprehensif. Pengetahuan tersebut didapatkan melalui berbagai sarana, salah satunya adalah pendidikan. Pendidikan merupakan cara yang paling penting dan efektif untuk memperoleh pengetahuan tentang kesehatan reproduksi, Pendidikan kesehatan merupakan semua kegiatan yang direncanakan untuk memberikan data atau meningkatkan pengetahuan orang lain baik individu, kelompok atau masyarakat dalam memelihara dan meningkatkan kesehatan mereka sendiri (Notoatmodjo, 2007; Ahmat Rifai, 2014).

Informasi tentang keputihan daat diperoleh dari teman sebaya atau peer group. Pendidikan oleh kelompok sebaya adalah suatu proses komunikasi, informasi, dan edukasi (KIE) yang dilakukan oleh dan untuk kalangan sebaya. Edukasi peer group merupakan upaya perubahan perilaku kesehatan melalui teman sebaya yang menekankan pada perubahan perilaku. Pada metode ini terjadi interaksi dalam kelompok, individu ajan merasa ada kesamaan satu dengan lainnya dan individu akan mengembangkan rasa sosial sesuai dengan perkembangan kepribadian (Romlah, 2001).

Remaja putri menganggap teman sebayanya sebagai sesuatu hal yang penting. Remaja menganggap kelompok sebayanya memberikan sebuah dunia tempat kawula muda mulai melakukan sosialisasinya, dimana nilai-nilai yang berlaku bukanlah nilai-nilai yang ditetapkan orang dewasa melainkan oleh temantemannya. Remaja banyak mengahabiskan waktu dengan teman-teman sebayanya melebihi waktu yang mereka habiskan dengan orang tua dan anggota keluarga yang lain (Indah, 2005; Eka Lestari 2012).

Pengetahuan reproduksi pada remaja sangat efektif dalam memengaruhi dan dipengaruhi oleh pengetahuan teman-tema sebayanya. Apabila teman sebaya memiliki pengetahuan kesehatan reproduksi yang memadai, mereka akan memberikan pengetahuan ini kepada temannya. Transfer pengetahuan ini mempunyai harapan agar mereka dapat memengaruhi temannya untuk mengambil keputusan yang sehat dan bertanggung jawab serta mampu melakukan kontrol terhadap dirinya. Populasi remaja yang cenderung meningkat, menyebabkan kebutuhan peningkatan pelayanan kesehatan dan sosial terhadap remaja semakin menjadi perhatian di seluruh penjuru dunia. Remaja seringkali kekurangan informasi dasar mengenai kesehatan reproduksi dan akses terhadap pelayanan kesehatan reproduksi yang terjangkau serta terjamin kerahasiaan (Purwoastuti, 2015, dalam Abrori, 2017).

Berdasarkan studi pendahuluan yang dilakukan pada siswi di SMP 1 Muhammadiyah Banjarmasin dengan membagikan kuesioner pada 20 siswi SMP 1 Muhammadiyah Banjarmasin diperoleh tingkat pengetahuan siswi tentang keputihan 15 siswi memiliki tingkat pengetahuan yang masih kurang. Sebagian besar siswi yaitu 14 orang mengaku belum pernah mendapatkan informasi tentang keputihan. Hasil wawancara dengan guru BK menyatakan bahwa belum ada kegiatan untuk meningkatkan pengetahuan siswi tentang kesehatan reproduksi khususnya keputihan.

\section{B. METODE PENELITIAN}

Penelitian ini merupakan penelitian yang menggunakan penelitian Quasy Eksperimental Pretespostest dengan kelompok kontrol (Prestest-Posttest with Control Group) (Nursalam, 2014: 166). Penelitian dilakukan pada bulan Novemver-Desember 2019 di SMP 1 Muhammadiyah Banjarmasin. Populasi dalam penelitian ini adalah seluruh siswi kelas VII tahun ajaran 2019/2020 sebanyak 60 siswi. Pengambilan sampel dengan Teknik purposive sampling berdasarkan kriteria inklusi yaitu siswi yang sudah menstruasi, mengikuti keseluruhan kegiatan peer group dan bersedia menjadi responden, sedangkan kriteria eksklusinya adalah tidak berada di tempat saat pengambilan data. Berdasarkan kriteria tersebut diperoleh sampel 30 siswi. Penelitian ini dilakukan dengan mengukur perubahan tingkat pengetahuan tentang keputihan antara sebelum dan sesudah dilakukan peer group.

\section{HASIL DAN PEMBAHASAN HASIL}

\section{Analisis Univariat}

TABEL 1.

Pengetahuan Remaja Putri tentang Keputihan (Fluor Albus) sebelum dilakukan Pendidikan Kesehatan Menggunakan Metode Peer Group pada Kelompok Intervensi

\begin{tabular}{llcc}
\hline No. & Pengetahuan & $\begin{array}{c}\text { Frekuensi } \\
\text { (n) }\end{array}$ & $\begin{array}{c}\text { Persentase } \\
\text { (\%) }\end{array}$ \\
\hline 1. & Baik & 6 & 40 \\
\hline 2. & Kurang baik & 9 & 60 \\
\hline Jumlah & & 15 & $100 \%$ \\
\hline
\end{tabular}

Berdasarkan Tabel 1 menggambarkan bahwa dari 15 responden yang memiliki pengetahuan baik sebelum dilakukan pendidikan kesehatan pada kelompok intervensi sebanyak 6 orang siswi atau $40 \%$ dan yang mempunyai pengetahuan kurang baik sebanyak 9 orang siswi atau $60 \%$. 
TABEL 2.

Pengetahuan Remaja Putri tentang Keputihan (Fluor Albus) sesudah dilakukan Pendidikan Kesehatan menggunakan Metode Peer Group pada Kelompok Intervensi

\begin{tabular}{llcc}
\hline No. & Pengetahuan & $\begin{array}{c}\text { Frekuensi } \\
\text { (n) }\end{array}$ & $\begin{array}{c}\text { Persentase } \\
\text { (\%) }\end{array}$ \\
\hline 1. & Baik & 15 & 100 \\
\hline 2. & Kurang baik & 0 & 0 \\
\hline Jumlah & 15 & $100 \%$ \\
\hline
\end{tabular}

Berdasarkan Tabel 2 menggambarkan bahwa dari 15 responden yang memiliki pengetahuan baik sesudah dilakukan pendidikan kesehatan pada kelompok intervensi sebanyak 15 orang siswi atau 100\% dan yang mempunyai pengetahuan kurang baik sebanyak o orang siswi atau $\mathrm{0} \%$.

TABEL 3.

Pengetahuan Remaja Putri tentang Keputihan (Fluor Albus) sebelum dilakukan Pendidikan Kesehatan menggunakan Metode Peer Group pada Kelompok Kontrol

\begin{tabular}{llcc}
\hline No. & Pengetahuan & $\begin{array}{c}\text { Frekuensi } \\
\text { (n) }\end{array}$ & $\begin{array}{c}\text { Persentase } \\
\text { (\%) }\end{array}$ \\
\hline 1. & Baik & 7 & 46,7 \\
\hline 2. & Kurang baik & 8 & 53,3 \\
\hline Jumlah & 15 & $100 \%$ \\
\hline
\end{tabular}

Berdasarkan Tabel 3 menggambarkan bahwa dari 15 responden yang memiliki pengetahuan baik sebelum dilakukan pendidikan kesehatan pada kelompok kontrol sebanyak 7 orang siswi atau 46,66\% dan yang mempunyai pengetahuan kurang baik sebanyak 8 siswi atau 53,33\%.

TABEL 4.

Pengetahuan Remaja Putri tentang Keputihan (Fluor Albus) sesudah dilakukan pendidikan kesehatan menggunakan metode peer group pada kelompok kontrol

\begin{tabular}{llcc}
\hline No. & Pengetahuan & $\begin{array}{c}\text { Frekuensi } \\
\text { (n) }\end{array}$ & $\begin{array}{c}\text { Persentase } \\
\text { (\%) }\end{array}$ \\
\hline 1. & Baik & 8 & 53,3 \\
\hline 2. & Kurang baik & 7 & 46,7 \\
\hline \multicolumn{2}{l}{ Jumlah } & 15 & $100 \%$ \\
\hline
\end{tabular}

Berdasarkan Tabel 4 menggambarkan bahwa dari 15 responden yang memiliki pengetahuan baik sesudah dilakukan pendidikan kesehatan pada kelompok kontrol sebanyak 8 orang siswi atau 53,3\% dan yang mempunyai pengetahuan kurang baik sebanyak 7 orang siswi atau $46,7 \%$.

Pada penelitian ini menggunakan uji statistic paired sampel $t$-test. Paired sampel $t$-test digunakan untuk mengetahui apakah terdapat perbedaan rata-rata dari dua sampel yang berpasangan, uji paired sampel $t$ test merupakan bagian dari statistik parametrik oleh karena itu sebagaimana aturan dalam statistik parametrik data penelitian harus berdistribusi normal.
Karena responden berjumlah 30 orang maka uji normalitas yang digunakan adalah Shapiro-wilk dan berdasarkan hasil uji t dengan menggunakan aplikasi komputerisasi didapatkan hasil data terdistribusi normal karen a nilai signifikan 2 tailed $>0,05$ artinya karena data terdistribusi normal maka uji paired sampel t test bisa digunakan dalam penelitian ini.

\section{Analisis Bivariat}

TABEL 5.

Pengaruh Pendidikan Kesehatan Metode Peer Group pada Kelompok Intervensi

\begin{tabular}{|c|c|c|c|c|c|c|c|}
\hline \multirow[t]{3}{*}{ No } & \multirow[t]{3}{*}{$\begin{array}{l}\text { Pengetah } \\
\text { uan }\end{array}$} & \multicolumn{4}{|c|}{$\begin{array}{c}\text { Pendidikan } \\
\text { Kesehatan }\end{array}$} & \multicolumn{2}{|c|}{ Mean } \\
\hline & & \multicolumn{2}{|c|}{$\begin{array}{l}\text { Pre- } \\
\text { test }\end{array}$} & \multicolumn{2}{|c|}{ Post-test } & \multirow{2}{*}{$\begin{array}{l}\text { Pre } \\
\text {-test }\end{array}$} & \multirow{2}{*}{$\begin{array}{c}\text { Post- } \\
\text { test }\end{array}$} \\
\hline & & $\mathrm{n}$ & $\%$ & $\mathrm{n}$ & $\%$ & & \\
\hline 1. & Baik & 6 & $\begin{array}{l}40 \\
\%\end{array}$ & 15 & $\begin{array}{c}100 \\
\%\end{array}$ & 14.2 & 17.8 \\
\hline \multirow[t]{3}{*}{2.} & $\begin{array}{c}\text { Kurang } \\
\text { Baik }\end{array}$ & 9 & $\begin{array}{c}60 \\
\%\end{array}$ & 0 & $0 \%$ & & \\
\hline & Jumlah & 15 & $\begin{array}{c}100 \\
\%\end{array}$ & 15 & $\begin{array}{c}100 \\
\%\end{array}$ & & \\
\hline & \multicolumn{7}{|c|}{ Uji Paired t-test : $p=0,001$} \\
\hline
\end{tabular}

Berdasarkan hasil uji korelasi menggunakanan Paired $t$-test pada tabel menunjukkan bahwa nilai $p=$ o,001 $(p<0,005)$ maka Ho ditolak dan Ha diterima, berarti ada pengaruh pemberian pendidikan kesehatan menggunakan metode peer group terhadap pengetahuan remaja putri tentang keputihan (fluor albus).

TABEL 6.

Pengaruh Pendidikan Kesehatan Metode Peer Group pada Kelompok Kontrol

\begin{tabular}{|c|c|c|c|c|c|c|c|}
\hline \multirow[t]{3}{*}{ No } & \multirow[t]{3}{*}{$\begin{array}{l}\text { Pengetah } \\
\text { uan }\end{array}$} & \multicolumn{4}{|c|}{$\begin{array}{c}\text { Pendidikan } \\
\text { Kesehatan }\end{array}$} & \multicolumn{2}{|c|}{ Mean } \\
\hline & & \multicolumn{2}{|c|}{ Pre-test } & \multicolumn{2}{|c|}{$\begin{array}{c}\text { Post- } \\
\text { test }\end{array}$} & \multirow{2}{*}{$\begin{array}{l}\text { Pre } \\
- \\
\text { test }\end{array}$} & \multirow{2}{*}{$\begin{array}{c}\text { Pos } \\
t- \\
\text { tes } \\
t\end{array}$} \\
\hline & & $\mathrm{N}$ & $\%$ & $\mathrm{n}$ & $\%$ & & \\
\hline 1. & Baik & 7 & $\begin{array}{c}46,7 \\
\%\end{array}$ & 8 & $\begin{array}{c}53,3 \\
\%\end{array}$ & 14.5 & 14.7 \\
\hline \multirow[t]{2}{*}{2.} & $\begin{array}{c}\text { Kurang } \\
\text { Baik }\end{array}$ & 8 & $\begin{array}{c}53,3 \\
\%\end{array}$ & 7 & $\begin{array}{c}46,7 \\
\%\end{array}$ & & \\
\hline & Jumlah & 15 & $\begin{array}{c}100 \\
\%\end{array}$ & 15 & $\begin{array}{c}100 \\
\%\end{array}$ & & \\
\hline
\end{tabular}

Berdasarkan hasil uji korelasi menggunakanan Paired t-test pada table 6 menunjukkan bahwa nilai $\mathrm{p}=$ o,251 ( $p>0,005$ ) maka Ho diterima dan Ha ditolak, berarti tidak ada pengaruh pemberian pendidikan kesehatan menggunakan metode peer group terhadap pengetahuan remaja putri tentang keputihan (fluor albus). Berdasarkan hasil uji korelasi menggunakanan Paired t-test pada tabel menunjukkan bahwa nilai $\mathrm{p}=$ o,251 ( $p>0,005$ ) maka Ho diterima dan Ha ditolak, berarti tidak ada pengaruh pemberian pendidikan kesehatan menggunakan metode peer group terhadap pengetahuan remaja putri tentang keputihan (fluor albus). 


\section{PEMBAHASAN}

Pendidikan kesehatan menggunakan metode peer group diberikan selama 5 hari, melalui peer educator dibagi secara langsung menjadi kelompok kecil dari 15 responden sebelum dilakukan pendidikan kesehatan menggunakan metoe peer group pada kelompok intervensi diberikan kuisioner terlebih dahulu setelah itu didapatkan hasil 6 orang siswi atau 40\% sisiwi memiliki pengetahuan yang baik dan 9 orang siswi memiliki pengetahuan yang kurang baik atau 60\% hal ini dikarenakan kurangnya pengetahuan dan informasi remaja putri tentang kesehatan reproduksinya khususnya tentang keputihan (fluor albus), dan disebabkan juga oleh minimnya pengetahuan tentang kesehatan reproduksi karena akses remaja mendapatkan informasi sangat terbatas.

Orang tua yang seharusnya menjadi agen sosialisasi yang utama dan pertama (premier) justru tidak memberikan persoalan-persoalan yang berkaitan dengan kesehatan reproduksi secara transparan karena masih dianggap tabu atau masih menganggap bahwa anaknya masi kecil dan belum layak untuk membicarakan perihal kesehatan reproduksi, atau bahkan para orang tua tidak banyak yang mengetahui dan memahami secara baik perihal informasi kesehatan reproduksi (Ali Imron, 2014). Sesudah diberikan pendidikan kesehatan menggunakan metode peer group, pengetahuan siswi tentang keputihan meningkat, dari 6 orang siswi yang memiliki pengetahuan baik meningkat menjadi 15 orang (100\%), sehingga bisa dikatakan seluruh responden pada kelompok intervensi mengalami peningkatan pengetahuan.

Hasil penelitian ini menunjukkan bahwa metode dengan peer group sangat berpengaruh dengan baik hal ini dikarenakan dalam peer group terjalin hubungan yang erat dan bersifat pribadi, peer group merupakan insitusi kedua setelah keluarga yang memiliki peranan yang sangat penting bagi kehidupan remaja (Vembriarto, 2014). Pengetahuan reproduksi pada remaja sangat efektif dalam memengaruhi dan dipengaruhi oleh pengetahuan teman-teman sebayanya. Apabila teman sebaya memiliki pengetahuan kesehatan reproduksi yang memadai, mereka akan memberikan pengetahuan ini kepada temannya. Transfer pengetahuan ini mempunyai harapan agar mereka dapat memengaruhi temannya untuk mengambil keputusan yang sehat dan bertanggung jawab serta mampu melakukan kontrol terhadap dirinya. Populasi remaja yang cenderung meningkat, menyebabkan kebutuhan peningkatan pelayanan kesehatan dan sosial terhadap remaja semakin menjadi perhatian di seluruh penjuru dunia. Remaja seringkali kekurangan informasi dasar mengenai kesehatan reproduksi dan akses terhadap pelayanan kesehatan reproduksi yang terjangkau serta terjamin kerahasiaan (Abrori, 2017).

Hasil yang didapatkan oleh peneliti sesuai dengan penelitian siti rofi'ah dkk, 2017 bahwa Pendidikan kesehatan metode peer group (teman sebaya) akan memberikan efek yang lebih positif. Dengan teman sebaya, remaja akan lebih terbuka dan lebih mudah berkomunikasi dibandingkan dengan orang tua dan guru, informasi yang sensitif dan kurang nyaman jika disampaikan oleh orang dewasa dapat tersampaikan oleh teman sebaya dengan menggunakan bahasa sesuai usianya. Dengan demikian, informasi lebih lengkap, mudah dipahami dan pada akhirnya tujuan dapat dicapai. Selain itu, sebagai peer educator teman sebaya tidak hanya memberikan informasi namun juga sebagai role model dalam berperilaku yang sehat, sehingga dapat disimpulkan adanya pengaruh pendidikan kesehatan oleh peer educator terhadap pengetahuan remaja putri tentang keputihan (fluor albus) melalui pemberian pendidikan kesehatan menggunakan metode peer group.

Hasil hipotesis dalam penelitian ini dengan menggunakan uji paired $t$-test didapatan nilai $p=0,001$, yang berarti lebih kecil darinilai $p<\alpha$ 0,005, sehingaa ada pengaruh pendidikan kesehatan menggunakan metode peer group terhadap pengetahuan remaja putri tentang keputihan (fluor albus).

Pada kelompok kontrol peningkatan pengetahuan sebelum dan sesudah diberikan pendidikan kesehatan hanya terdapat sedikit perbedaan. Berdasarkan hasil penelitian pada kelompok kontrol, sebelum dilakukan pendidikan kesehatan yang memiliki pengetahuan baik ada 7 orang sisiwi atau $46,7 \%$ dan yang memiliki pengetahuan kurang baik ada 8 orang sisiwsi atau 53,3\%, sedangkan setelah dilakukan pendidikan kesehatan ada 8 orang sisiwi yang mempunyai pengetahuan baik atau $53,3 \%$ dan yang kurang baik ada 7 orang siswi atau 46,7\%. Berdasarkan hasil penelitian ini bisa dilihat bahwa perbedaan hasilnya sangat sedikit, hal ini membuktikan bahwa pemberian pendidikan kesehatan dengan leaflet saja kurang efektif apabila dibandingkan dengan pendidikan kesehatan metode peer group. Kelompok kontrol hanya diberikan pendidikan kesehatan menggunakan leaflet tidak dengan intervensi metode peer group karena kelompok kontrol merupakan kelompok pembanding untuk mengetahui efektif tidaknya pendidikan kesehatan dengan metode peer group.

Faktor lingkungan merupakan kondisi yang dapat mempengaruhi perkembangan dan perilaku orang atau kelompok. Dan di karenakan oleh kemajuan teknologi dan perubahan sosial, pola pendidikan orang tua sebagian tidak berubah. Informasi tentang kesehatan reproduksi dan seksualitas masih tabu untuk dibicarakan, akibatnya remaja justru mendapat informasi salah yang menejerumuskan mereka (Koes Irianto, 2015:1). Ini menyebabkan remaja mendapatkan informasi dan pengetahuan yang salah tentang kesehatan reproduksi sehingga mereka memiliki pengetahuan yang kurang karena tidak adanya sumber informasi yang jelas dan arahan atau pembelajaran tambahan tentang kesehatan reproduksi. 


\section{SIMPULAN DAN SARAN}

Hasil penelitian menunjukkan sebelum dilakukan pendidikan kesehatan dengan metode peer group, 60\% tingkat pengetahuan remaja putri tentang keputihan pada kategori kurang baik. Setelah diberikan intervensi pendidikan kesehatan dengan metode peer group, 100\% tingkat pengetahuan remaja putri tentang keputihan pada kategori baik. Pendidikan kesehatan dengan metode peer group memiliki pengaruh terhadap tingkat pengetahuan remaja putri ( $p$ value 0,001 ) tentang keputihan. Disarankan kepada guru BK SMP 1 Muhammadiyah Banjarmasin agar menggunakan metode peer group untuk meningkatkan pengetahuan remaja putri terkait kesehatan reproduksi khususnya masalah keputihan sehingga mereka mendapatkan informasi yang akurat dan diharapkan bisa mencegah terjadinya ganguan kesehatan reproduksi pada remaja putri.

\section{DAFTAR RUJUKAN}

[1] Abrori, "Faktor Yang Berhubungan Dengan Kejadian Keputihan Patologis Siswi Sman 1 Simpang Hilir Kabupaten Kayong Utara”. Unnes Journal of Public Health $6(1), 2017$.

[2] Darma, M, "Hubungan Pengetahuan, Vulva Hygiene, Stres, Dan Pola Makan Dengan Kejadian Infeksi Flour Albus (Keputihan) Pada Remaja Siswi Sma Negeri 6 Kendari”, Jurnal Ilmiah Mahasiswa Kesehatan Masyarakat Vol. 2/No.6, Mei 2017.

[3] Imron, A.,"Pendidikan Kesehatan Reproduksi Remaja ArRuzz Media”, Jogjakarta, 2014.

[4] Irianto, K, Kesehatan Reproduksi Reproductive Health Teori Dan Praktikum. Alfabeta, Bandung, 2015.

[5] Kusmiran, E, Kesehatan Reproduksi Remaja dan Wanita. Salemba Medika, Jakarta Selatan, 2011.

[6] Lestari, E,"Hubungan Peer Group Dan Lingkungan Pergaulan Dengan Perilaku Seksual Pranikah Pada Siswa" Disertasi, Universitas Muhammadiyah Banjarmasin, 2012.

[7] Nursalam, Metodologi penelitian Ilmu Keperawatan. Salemba medika, Jakarta selatan, 2014.

[8] Ramauli, S, dan Vindari, A. V, Kesehatan Reproduksi Buat Mahasiswi Kebidanan. Cetakan I. Yogyakarta: Penerbit Nuha Medika, 2011.

[9] Rifai, A., "Hubungan Pengetahuan Kebutuhan Penggunaan Alat Pelindung Diri (APD) Dengan Resiko Luka Bakar Pada Petugas Pemadam Kebakaran Diwilayah Kerja Manggala Agni Banjarbaru” Disertasi, Universitas Muhammadiyah Banjarmasin, 2014.

[10] Romlah, T, Teori dan Praktek Bimbingan Kelompok. Malang: UN, 2001.

[11] Sari, P."Hubungan Antara Pengetahuan Dan Sikap RemajaDengan Kejadian Fluor Albus Remaja Putri Smkf X Kediri”. Jurnal Wiyata, Vol. 3 No. 1., 2016.

\section{PROFIL PENULIS UTAMA}

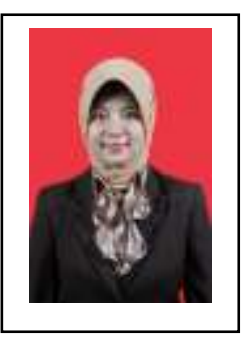

Domas Nurchandra Pramudianti, merupakan dosen prodi D-3 Kebidanan Universitas Muhammadiyah Banjarmasin, lulusan S2 Kebidanan Universitas 'Aisyiyah Yogyakarta tahun 2017. 